\title{
Explicit and Implicit Anti-Fat Attitudes in Children and Their Relationships with Their Body Images
}

\author{
Irene Solbes Ileana Enesco \\ Departamento de Psicologia Evolutiva, Facultad de Psicología, Universidad Complutense de Madrid, Spain
}

\section{Key Words}

Explicit attitudes · Implicit attitudes · Body image · Overweight $\cdot$ Children

\section{Summary}

Objective: This study aimed to explore the prevalence of negative attitudes toward overweight peers among children using different explicit and implicit measures, and to analyze their relationships with some aspects of their body image. Method: A total of 120 children aged 6-11 years were interviewed using a computer program that simulated a game containing several tasks. Specifically, we have applied multiple measures of explicit attitudes toward average-weight/overweight peers, several personal body attitudes questions and a child-oriented version of the Implicit Association Test. Results: Our participants showed important prejudice and stereotypes against overweight children, both at the explicit and implicit levels. However, we found important differences in the intensity of prejudice and its developmental course as a function of the tasks and the type of measurement used to assess it. Conclusions: Children who grow up in Western societies idealize thinness from an early age and denigrate overweight, to which they associate explicitly and implicitly a series of negative traits that have nothing to do with the weight. As they grow older, they seem to reduce their levels of explicit prejudice, but not the intensity of implicit bias. More research is needed to study in depth prejudice and discrimination toward overweight children from a developmental point of view.

\section{Introduction}

According to the latest report of the International Group on Obesity [1], about 155 million children suffer from overweight all over the world (1 out of every 10). In Europe, overweight and obesity rates in children and youngsters have increased considerably in the last two decades so that $20 \%$ of European schoolchildren are currently overweight.

This problem, with important global economic and healthrelated consequences [2], should also be analyzed from the perspective of those who suffer from overweight because they frequently become particularly vulnerable targets of prejudice and societal stigmatization. Along with clearly harmful effects for health, obesity currently represents a deviation from the beauty canon in Western societies. Thus, these people suffer two-fold: on the one hand, because their health is more vulnerable, and on the other, because they must deal with societal stigmatization [3, 4].

Within this context, whereas overweight is approaching the proportions of an epidemic, we also observe a generalized increase in behaviors associated with eating disorders, especially among women and adolescent population [5]. Body dissatisfaction seems to be one of the most determinant risk factors for developing this kind of pathology [6], along with social pressure exerted on body image.

These two kinds of problems (overweight and eating disorders) are apparently opposed; however, they are frequently related in the long term. For example, being overweight during childhood is one of the risk factors associated with the onset of eating disorders in adolescence and adulthood [7]. This relation could be mediated in some way by the social reaction of people from the overweight child's setting. Research shows that suffering teasing and weight-related criticism is associated with unhealthy eating behaviors, the onset of binge eating, and an increased risk for obesity [8].

\begin{tabular}{ll}
\hline KARGER & $\oplus$ 2010 S. Karger GmbH, Freiburg \\
Fax +497614520714 & Accessible online at: \\
Information@Karger.de & www.karger.com/ofa \\
www.karger.com &
\end{tabular}


The recent increase in the prevalence of eating disorders seems to be, at least partly, the consequence of a very harmful paradox observed in Western societies. Whereas the population is in general heavier, mass media spread a beauty canon that is skewed toward increasing thinness [9], and, at the same time, they present very stereotyped and prejudiced images of overweight people [10]. Assuming this obvious contradiction between ideal body and real body and adapting it to the childhood, one could say that our children and youth are increasingly fatter, whereas ideal of beauty that we transmit to them from a very early age is very often associated with extreme thinness (think about bodies of Barbie or Bratz dolls).

Psychology has spent more than 40 years investigating people's attitudes toward overweight as a potentially stigmatizing characteristic [11, 12]. Empirical evidence accumulated over the years shows that overweight people are usually attributed a broad range of negative stereotypes $[3,13,14]$ and that, as a consequence, they suffer discrimination in many areas of their lives: work, health system, education and interpersonal relations [4]. Contrary to what is normally thought, social rejection suffered by overweight individuals does not motivate them to reduce weight, but results in the opposite effect: they report coping with stigma often by eating more and refusing to diet [4]. Furthermore, recent studies indicate that stress associated with weight stigmatization exacerbate previous health problems like hypertension, impaired glucose tolerance or insulin resistance [15].

Research with children in this area is still scarce in comparison with studies of other types of attitudes in childhood (ethnic-racial, gender). Nevertheless, evidence accumulated until now shows that overweight children run considerable risk of becoming victims of bias and stereotyping. For example, when they are presented a set of photos or drawings depicting children with different body sizes, overweight children are usually rejected for playing or working in the classroom; they are never chosen as models and they are often targets of negative attributions [16-19]. Moreover, the content of the stereotypes associated with overweight children has a lot in common with traits normally attributed to overweight adults: lazy, dirty, mean, ugly, stupid, sick and with few academic, social, athletic or artistic abilities [20-24]. Considering the social perception that people have about them, it is not surprising that overweight children are particularly vulnerable to depressive symptoms, low self-esteem and body dissatisfaction [25, 26].

In recent years, anti-fat research has focused on different aspects related to the nature of weight bias in order to design stigma reduction interventions and elucidate the role of these prejudices in childhood obesity prevention. Studies focused on the influence of variables such as gender [16, 27, 28], ethnic background [27, 28], attributions about causality of obesity [30] or body weight. In this regard, empirical evidence suggests that overweight adults and children usually hold anti-fat attitudes to the same extent as average-weight people [16,31], highlighting the pervasiveness of this stigmatism and the lack of in-group favoritism characteristic of other minority groups. However, recent work [17] suggests that perceived body size may be a better predictor than actual body size of children's attitudes toward overweight individuals because weight status seems to be relatively subjective and, in many cases, unrelated to real weight [32].

Studies show that weight bias begins early in childhood [16, 20,33]. According to the results of Cramer and Steinwert [16], already at the age of 3 , children attributed negative traits to the figure of an overweight child, chose this figure as the one they did not want look like, and rejected it as a possible playmate. However, little is known about the developmental course of this kind of attitudes over childhood and adolescence. Studies about anti-fat prejudices carried out with children of different ages yield less conclusive results than those from the field of racial prejudice, the open expression of which tends to decrease as children approach adolescence $[34,35]$. On the one hand, several studies find increases in these biases throughout school years until pre-adolescence [16, 19, 24, 29], attributing it to the progressive internalization of weightrelated concerns and aesthetic norms [36, 37]. Nevertheless, according to other studies, this stigmatization look to be relatively stable from the first years of formal education [20, 38], and in some works it suffers even slight reductions with age $[18,21,22,39]$. Part of these differences may be due to different procedures and measures of prejudice used in each study.

Negative attitudes toward overweight people during childhood have been studied in all cases by means of diverse selfreport measures, inspired by classic studies on ethnic prejudice in children [40]. Basically, participants are presented a set of drawings or pictures depicting children with different body types and asked to make different choices or to assign them several attributes. For this reason, we cannot know whether reductions found in some of the studies mentioned above reveal a real fall in levels of anti-fat bias or, on the contrary, are just showing a decrease in its open expression, but not in the individual's internal attitude. Various authors tend toward this latter interpretation when they study ethnic prejudices [41], proposing that children acquire positive social values against prejudice and discrimination early in life and, as a consequence, learn to conceal their true inclinations, displaying egalitarian response patterns in tasks whose goal (to measure prejudice) is 'transparent'.

Social psychology of the last decades has assumed that children's and adults' attitudes, stereotypes and group identities can operate in a non-conscious or implicit form [42] and that these mental representations are distinguishable from 'explicit', conscious cognition at both the behavioral [43] and the neural level [44]. Works carried out with adults seem to indicate that, in the context of discrimination, implicit attitudes are often better predictors of discriminatory behavior than traditional measures of prejudice [45]. For example, one study found that implicit attitudes, but not explicit attitudes, predicted how far individuals chose to sit from an overweight person [46]. 
Explicit attitudes can be assessed using direct or selfreport measures, because people usually are willing and able to report them. According to Fazio [47], these biases guide our behavior when a deliberate and conscious analysis has been applied to the task. On the other hand, when there is little motivation or opportunity to engage in controlled processing, implicit attitudes are automatically activated by the simple presence (real or symbolic) of certain targets or objects that elicit the attitude, generally operating at an unconscious level [48]. Implicit attitudes are thought to reflect evaluations that people are either unwilling or unable to report [42], either because of self-presentation concerns or because they are unaware of possessing the biases in the first place.

The few studies conducted with children about automatic bias show that implicit prejudices toward different racial groups could appear very early in life $[49,50]$, around 5 years of age, and that they are relatively stable throughout life. To date, we know of no study that analyzes implicit attitudes toward overweight people in childhood although in recent years several works have been carried out on this issue with adult population $[14,51]$.

In this general context, the goal of the present study was to explore the presence of children's explicit and implicit attitudes toward different body types (average-weight/overweight) and their links with participants' personal body attitudes. We also wanted to study the relations between these three constructs. Finally, we wanted to examine whether explicit, implicit anti-fat and/or personal body attitudes predicted our participants' choices of possible partners for significant activities. This study constitutes a first and comprehensive approach to the research on anti-fat attitudes in children, applying multiple measures of different attitudinal components (both at explicit and implicit levels) and considering other important aspects related with participants' body image. Empirical developmental studies in this field should serve as a ground for developing educational efforts to reduce weight stigmatization and to promote general size acceptance among school age children.

\section{Participants and Methods}

\section{Participants}

The total number of participants was 120 children (60 boys and 60 girls), registered at a school in the Region of Madrid and situated in a middleclass neighborhood. Children from three age groups participated in the study: 40 children from first grade $(6-7$ years, mean age $=6.9$ years), 40 from third grade $(8-9$ years, mean age $=8.9$ years $)$ and 40 from fifth grade $(10-11$ years, mean age $=10.8$ years $)$. Even if we did not get objective measures of children's body mass index, all of them were boys and girls with average body size.

All children who participated in the study did so voluntarily, with their parents' prior consent. The tests were administered in individual sessions lasting about $30 \mathrm{~min}$, during the normal school schedule, with the support of a laptop computer.

\section{Measures}

We designed a computer program that simulated a game with several tasks and activities to collect the data. The use of a laptop computer as support for the entire session allowed us to automatically record participants' choices and performance. Assessment sessions were made up of three sets of tasks.

\section{Explicit Measures of Attitudes}

The purpose of these tasks was to examine the attitudes elicited by a group of 8 unknown school age children (boys and girls) who presented two body types ( 4 of average-weight / 4 overweight). Targets were presented in photographs, all of them smiling, with the face and part of the bust shown. Some of the photos were slightly retouched by means of a graphic design program, to enlarge the body type of the depicted child so he or she would specifically fit the profile of an overweight child. The photographs were also modified to maintain a homogeneous background and clothing, thus eliminating the possible influence of this kind of characteristic. Even assuming that drawings (used in the majority of the research in this field) allow for higher homogeneity among the stimuli than photographs, we decided to work with photos to lend more realism to the tasks. Attractiveness of the children presented in the photographs was judged by 20 adults. This group rated overweight targets as slightly less attractive than the average-weight targets. As overweight individuals are generally judged as less attractive than average-weight individuals [52], it may be impossible to control this variable in studies based on photos.

To introduce the first set of questions, we proposed to the participants a supposed exchange situation among schools, with the following introduction: 'I am going to show you some photographs of boys and girls from another school. Imagine that these children are going to spend a few weeks at your school. I want you to look closely at their photographs and to answer some questions about them'.

Simple preferences and rejections task: The task began with a first screen on which the four photos of boys ( 2 overweight and 2 averageweight) were presented. Participants were asked to state their preferences and rejections ('Look closely at the photos of these children and tell me: Which one of the four you see here do you like the most / the least?'). When they had chosen a couple of children, the same questions were asked about a next screen that showed the four photos of girls. The photographs were always presented randomly on the screen (for each participant and in each task) to avoid a possible spatial effect on the participants' choices.

Children were allowed for a 'none' response (although frequency of this answers were very low), but they were not allowed to select more than one target in each trial (for example: 'I would like to play with all of them'). In these cases, the interviewer persuaded the child to choose just one ('Ok, you like all ... but which one would you prefer the most to play with?'). The few children that gave this first answer did not show any trouble to change their mind and to select just one of the photos.

Sociometric task: In this task, participants would choose and reject possible partners to carry out various activities proposed in three significant contexts: working together in class, playing in the school-yard, and going to a birthday party in the child's own home. As examples, we present the instructions employed in the schoolyard context: 'When the children from the other school are visiting here, they will go down to the yard with you at recess. Let's do like we did before, look closely at these four boys and tell me: Which one would you like to play with at recess? Fine ... and now: Which one wouldn't you like to play with?' As in the previous task, two trials of each type (one with photos of boys and one with photos of girls) were carried out.

Adjective attribution task: At this point, six stories were presented to the children. In each story, there was a character that showed a positive (nice, smart or clean) or a negative attribute (mean, stupid or dirty). In each case, participants had to choose from the four photos presented the one that could represent the character. For example, the following story 
was presented for the attribution of the adjective 'nice': 'This story is about a girl who is very nice: she rescues abandoned animals, like this kitten, she takes them home, cares for them, and feeds them. Look, one of these four girls is the nice girl, the one who rescues abandoned animals and takes them home. Who do you think she is?'.

\section{Personal Body Attitudes}

In order to determine children's body size identification and their attitudes toward their own body type, participants were shown an array of seven drawings of figures ranging from severe underweight to severe overweight adapted from Collins' material and procedure [53]. Looking at these figures, three questions were asked: i) 'Which one do you look like?' (self-identification); ii) 'Which would you most like to look like?' (ideal identification), and iii) 'Which do you not want to look like?' (averted identification).

\section{Implicit Measure of Attitudes}

To measure implicit stereotyping toward overweight people, participants carried out an Implicit Association Test (IAT) [54] in a child-oriented version adapted from Baron and Banaji [49]. The IAT has been used in many works to assess adults' implicit bias related to various social groups, such as attitudes toward men/women [55], Whites/Blacks [56], or thin/fat people [14]. The IAT measures the association between a target concept (in our case, body type: average-weight/overweight children) and an attribute dimension (positive/negative attributes).

The instrument is made up of 5 blocks of trials, where certain items must be classified using two computer keys. In the first block, participants were requested to classify a series of images as they appeared on the middle of the screen. For this block, we used various figures of average-weight and overweight children, which we labeled 'thin' and 'fat' (we used the label 'delgado' in Spanish ('thin' in English) for designating children with average weight in the IAT. In Spanish, the term 'delgado' may refer both to slim and average body sizes, while the term 'gordo' ('fat' in English) refers to overweight people), to represent the two types of body sizes that we wished to compare. Stimuli were four schematic figures of average-weight and overweight boys and girls, created from figures 4 and 7 of Collins' array [53] varying the color of their hair and clothing. This material is an improvement over others employed in the study of implicit attitudes toward overweight, in which, instead of images, words such as 'chubby' or 'heavy' are used as exemplars of targets. As noted by some authors [57], these terms have a pejorative connotation, which could contaminate the results of the test. All figures employed represented children of the same gender as that of the participant.

In the second block, participants had to classify different words (positive and negative attributes presented auditorily) in two groups with the aid of the two corresponding computer keys again. Exemplars corresponding to the positive/negative attributes were the following: nice/ mean, smart/stupid, clean/dirty, and happy/sad.

In the third block (called 'stereotype congruent block'), participants had to complete several double-categorization tasks, with items representing the concept 'thin' and 'positive attributes' receiving one response key, and items representing the concept 'fat' and 'negative attributes' receiving the alternative response key. In the fourth block, items corre sponding to the two targets were again presented, but in this case the location of the keys was switched. In the last block (called 'stereotype incongruent block'), both types of items were presented but, in this case classification keys were incongruent with the stereotype socially shared ('fat' and 'positive attribute' having the same response key).

The underlying assumption of this test is that the greater association between the categories, participants will respond faster and more accurately to the congruent block as compared to the incongruent block. The order of the congruent (thin - positive) and incongruent (fat - positive) block was counterbalanced. Errors and response latencies were recorded in milliseconds.

\section{Data Analysis}

In each of the three tasks that made up the explicit measures set, we counted the frequency with which each of the two types of targets (average-weight/overweight children) was chosen by our participants. We conducted several 3 (age group: 6-7 vs. 8-9 vs. 10-11 years) $\times 2$ (body type: average-weight vs. overweight figures, henceforth AF-OF) ANOVAs with repeated measures in the second variable. The Games-Howell posthoc test was used to detect significant differences among the age groups.

Data for the personal body attitudes set were the number of the figure chosen in each case: the thinnest figure received a value of 1 and the heaviest figure had a value of 7 . We additionally obtained a body dissatisfaction score by calculating the discrepancy between self-identification and ideal identification.

Thirdly, for each subject, an IAT score was computed following the standard protocol for the improved scoring algorithm recommended by Greenwald et al. [58]. A variation of Cohen's $d$ index was obtained by calculating the difference between the mean response latencies for the two double-categorization blocks within each IAT and dividing that difference by its associated pooled standard deviation. Following Baron and Banaji [49], we obtained different scores for each type of stimulus (visual/auditive), calculating the mean score of both of them. We also verified that the presentation order of the two blocks of crossed categorization (congruent/ incongruent) had not produced any effect $(\mathrm{t}(118)=0.467, \mathrm{p}=0.641)$.

Finally, Pearson's correlations coefficients were used to examine the relationships between our different variables. Additional linear regression analysis were conducted to determine the amount of variance in sociometric scores obtained by both types of children presented (preferences of $\mathrm{AF}$, rejections of $\mathrm{OF}$ ) accounted for by the rest of variables considered in the study.

All analyses were carried out using SPSS 15.0 for Windows (Munich, Germany).

\section{Results}

A check for gender differences in each variable was performed, and no significant differences were found in any of the comparisons. Consequently, these subgroups were pooled in all analyses.

\section{Explicit Measures of Attitudes}

\section{General Results}

General scores obtained by AF and OF and results of statistical tests are shown in table 1. Globally, most of our participants chose one AF as the most liked. These targets were preferably chosen to share the diverse activities proposed and had been associated more likely with positive adjectives. On the other hand, OF were massively chosen as the most disliked children. Our participants also strongly rejected them to share different social activities and selected more negative characteristics for them than for AF targets.

\section{Age Differences}

Table 2 shows scores obtained by target figures by age group. With the goal of simplifying the results, we show only scores for preferences of AF and rejections of OF. As it can be seen in the table, all scores suffered drops of different magnitudes, 
Table 1. Means (and standard deviations) of figure choices in explicit measures

\begin{tabular}{|c|c|c|c|c|c|c|c|}
\hline & \multirow[t]{2}{*}{ Range } & \multicolumn{2}{|l|}{ Body figure } & \multirow[t]{2}{*}{ ANOVA $F$} & \multirow{2}{*}{$\begin{array}{l}d f s \\
\text { between }\end{array}$} & \multirow{2}{*}{$\begin{array}{l}d f s \\
\text { within }\end{array}$} & \multirow[t]{2}{*}{$\eta_{p}^{2}$} \\
\hline & & $\mathrm{AF}$ & $\mathrm{OF}$ & & & & \\
\hline Simple preferences & $0-2$ & $1.97(0.21)$ & $0.03(0.21)$ & $2644.03 * * *$ & 2 & 115 & 0.96 \\
\hline Simple rejections & $0-2$ & $0.17(0.40$ & $1.83(0.40$ & $530.70 * *$ & 2 & 114 & 0.82 \\
\hline Sociometric preferences & $0-6$ & $5.59(0.80)$ & $0.41(0.80)$ & $1314.49 * * *$ & 2 & 116 & 0.92 \\
\hline Sociometricrejections & $0-6$ & $0.83(1.21)$ & $5.17(1.21)$ & $426.30 * * *$ & 2 & 115 & 0.79 \\
\hline Positive attributes & $0-3$ & $2.22(0.92)$ & $0.78(0.92)$ & $95.89 * * *$ & 2 & 116 & 0.45 \\
\hline Negative attributes & $0-3$ & $1.08(1.08)$ & $1.92(1.08)$ & $27.83 * * *$ & 2 & 116 & 0.19 \\
\hline
\end{tabular}

$\mathrm{AF}=$ Average-weight figures, $\mathrm{OF}=$ overweight figures. $* \mathrm{p}<0.05 ; * * \mathrm{p}<0.01 ; * * \mathrm{p}<0.001$

Table 2. Means (and standard deviations) for age groups in explicit measures

\begin{tabular}{|c|c|c|c|c|c|c|c|c|}
\hline & \multicolumn{3}{|l|}{ Age group } & \multirow[t]{2}{*}{ ANOVA $F$} & \multirow{2}{*}{$\begin{array}{l}d f s \\
\text { between }\end{array}$} & \multirow{2}{*}{$\begin{array}{l}d f s \\
\text { within }\end{array}$} & \multirow[t]{2}{*}{$\eta_{\mathrm{p}}^{2}$} & \multirow{2}{*}{$\begin{array}{l}\text { Games- } \\
\text { Howell }^{\mathrm{a}}\end{array}$} \\
\hline & 6-7 years old (a) & 8-9 years old (b) & 10-11 years old (c) & & & & & \\
\hline Simple preferences AF & $1.97(0.16)$ & $2.00(0.00)$ & $1.95(0.32)$ & 0.613 & 2 & 115 & 0.01 & - \\
\hline Simple rejections OF & $1.95(0.22)$ & $1.85(0.36)$ & $1.68(0.52)$ & $4.55^{*}$ & 2 & 114 & 0.07 & $a>c$ \\
\hline Sociometric preferences AF & $5.60(0.81)$ & $5.82(0.45)$ & $5.35(0.97)$ & $3.73^{*}$ & 2 & 116 & 0.06 & $b>c$ \\
\hline Sociometric rejections OF & $5.25(1.12)$ & $5.64(0.62)$ & $4.62(1.49)$ & $7.98 * *$ & 2 & 115 & 0.12 & $\mathrm{~b}>\mathrm{c}$ \\
\hline Negative attributes $\mathrm{OF}$ & $2.56(0.75)$ & $2.12(.91)$ & $1.10(0.98)$ & $28.34 * * *$ & 2 & 116 & 0.33 & $a>c$ \\
\hline
\end{tabular}

$\mathrm{AF}=$ Average-weight figures, $\mathrm{OF}=$ overweight figures.

${ }^{a}$ Statistical significance was defined as $\mathrm{p}<0.05$ for post hoc tests.

$* \mathrm{p}<0.05 ; * * \mathrm{p}<0.01 ; * * * \mathrm{p}<0.001$

Table 3. Means (and standard deviations) for age groups in personal body attitudes scores

\begin{tabular}{|c|c|c|c|c|c|c|c|c|c|}
\hline & \multirow[t]{2}{*}{ General score } & \multicolumn{3}{|l|}{ Age group } & \multirow[t]{2}{*}{ ANOVA $F$} & \multirow{2}{*}{$\begin{array}{l}d f s \\
\text { between }\end{array}$} & \multirow{2}{*}{$\begin{array}{l}d f s \\
\text { within }\end{array}$} & \multirow[t]{2}{*}{$\eta_{\mathrm{p}}^{2}$} & \multirow{2}{*}{$\begin{array}{l}\text { Games- } \\
\text { Howell }^{\mathrm{a}}\end{array}$} \\
\hline & & 6-7 years old (a) & 8-9 years old (b) & $10-11$ years old $(\mathrm{c})$ & & & & & \\
\hline Self-identification & $3.86(0.92)$ & $3.58(1.05)$ & $3.83(0.84)$ & $4.18(0.78)$ & $4.46^{*}$ & 2 & 117 & 0.07 & $c>a$ \\
\hline Averted identification & $5.20(2.71)$ & $6.50(1.60)$ & $5.90(2.29)$ & $3.20(2.89)$ & $22.88 * * *$ & 2 & 117 & 0.28 & $a>b>c$ \\
\hline Ideal identification & $3.69(0.84)$ & $3.50(1.10)$ & $3.68(0.73)$ & $3.90(0.59)$ & 2.28 & 2 & 117 & 0.04 & - \\
\hline Body dissatisfaction & $0.17(1.02)$ & $0.08(1.28)$ & $0.15(0.92)$ & $0.28(0.81)$ & 0.38 & 2 & 117 & 0.00 & - \\
\hline
\end{tabular}

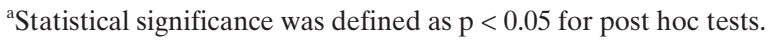

$* \mathrm{p}<0.05 ; * * \mathrm{p}<0.01 ; * * * \mathrm{p}<0.001$.

except for simple preferences of AF, which kept in very high and stable levels trough all the ages analyzed.

\section{Personal Body Attitudes}

Descriptive statistics of the different scores contained in this second set of tasks are shown in table 3 as well as the results of univariate analysis of variance applied to study the influence of age in our participants' identification choices.

\section{Self-Identification}

The mean for self-identification was 3.68. Figure number 4 (average-weight) was chosen as the most similar to themselves by more than half of the children $(52.5 \%)$. The second figure most frequently chosen as the most similar was number 5 $(22.5 \%)$, followed by number $3(15.8 \%)$ and by the two figures that represented thinnest children (1 and 2) (9.2\%). Analysis of variance indicated that body type of the figure chosen as the most similar became increasingly larger with age.

\section{Averted Identification}

The mean averted score was 5.20. Most of the participants $(70 \%)$ named either of the two heaviest figures (number 6 or 7 ) as the one that they would not like to look like. However, $29.2 \%$ chose one of the skinniest figures in this task, whereas one participant $(0.8 \%)$ chose figure number 3. Again, effect of age was significant, with the mean decreasing notably in all 
Fig. 1. Mean ( \pm SEM, indicated by the error bars) latencies (in ms) for congruent and incongruent blocks.

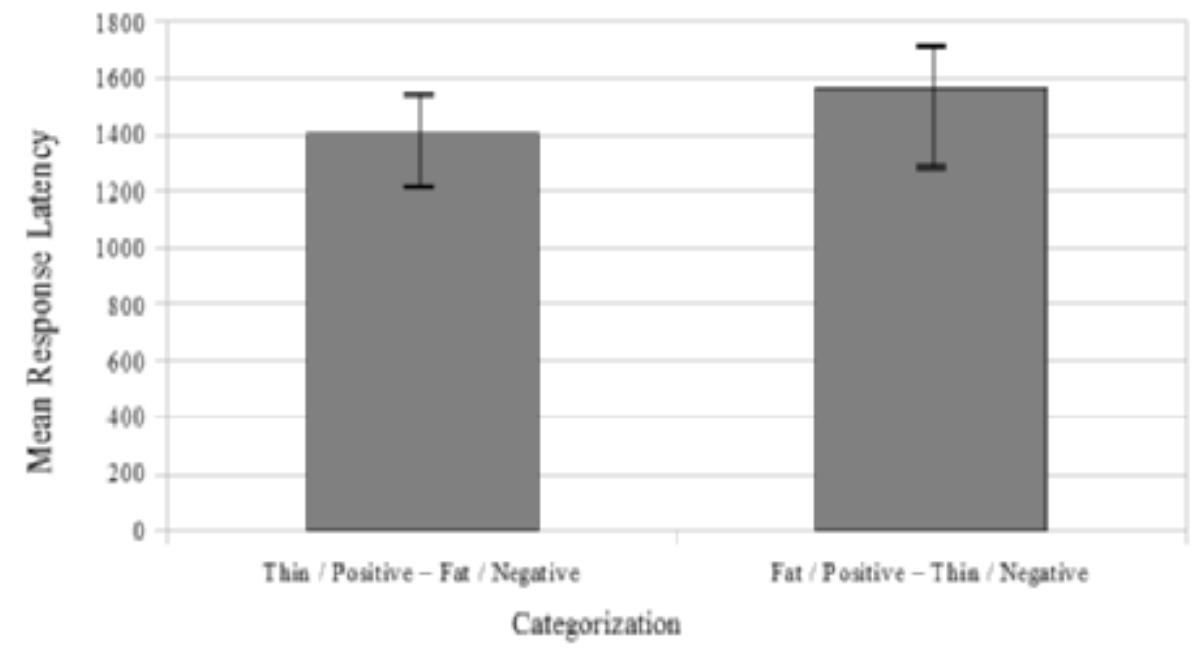

three groups. These differences are due to the fact that most of the youngest participants rejected the heaviest figures (numbers $6(92.5 \%)$ and $7(82.5 \%)$, whereas the thinnest figures (numbers 1 and 2) were rejected more frequently by the older participants $(62.5 \%)$.

\section{Ideal Identification}

The mean for ideal self was 3.69, a value very close to that of self-identification. Both scores underwent an almost identical development across the three age groups, although in this case age only reached a value close to significance $(\mathrm{p}=0.093)$. The figure preferred by most of the participants as the one that represented the ideal body was the intermediate figure number $4(60.8 \%)$, followed by number $3(22.5 \%)$. Only a small minority chose one of the thinnest figures $(7.5 \%)$, slightly overweight figure $(8.3 \%)$, or heaviest figures $(0.8 \%)$.

\section{Body Dissatisfaction}

Examination of the discrepancy between self and ideal ratings revealed that the mean of this score was very low $(\mathrm{M}=0.17)$. Of all participants, $42 \%$ was satisfied with their body type, as they chose the same figure in both questions. Among the children who displayed some kind of body dissatisfaction, $38 \%$ wished to be thinner and $20 \%$ wished to be heavier. Participant's body dissatisfaction suffered a slight increase with the age (table 3) although the effect of this variable did not reach statistical significance.

\section{$I A T$}

As figure 1 shows, participants hold implicit pro-average/antioverweight associations, observed in faster responding on 'congruent trials' than on 'incongruent trials' (mean difference $=161 \mathrm{~ms})$. The average IAT effect was significant $(\mathrm{D}=$ 0.35 (effect size conventions for $\mathrm{d}$ are as follows: small $=0.20$, medium $=0.50$, and large $=0.80[68]), \mathrm{SD}=0.3, \mathrm{t}_{(119)}=-7.744$, $\mathrm{p}<0.001$ ), revealing a relative positive association between average-weight and positive attributes and overweight and negative attributes.

Considering the valence of the scores, we confirmed that $84.2 \%$ of the participants obtained a positive score: they associated more quickly images of overweight children with negative attributes and images of average-weight children with positive attributes, indicating implicit weight-based stereotyping. However, $15 \%$ of them obtained a negative score, whereas one participant obtained an exact score of 0 . Correspondent ANOVA showed that age differences were non-significant. On the other hand, girls obtained higher scores than boys although these differences only reached a value close to significance $(\mathrm{p}=0.068)$.

\section{Relationship between Variables}

Results of the bivariate correlation analyses are given in table 4. As can be noticed, we found high correlations among the different explicit measures of anti-fat bias. In contrast, at a global level, implicit negative bias toward overweight children (IAT score) were not related to any of the other variables considered. However, in the youngest group of participants (data not shown in the table), the IAT correlated with two of the explicit measures: positive adjectives attributed to AF $(\mathrm{r}=$ $0.33, \mathrm{p}<0.05)$ and negative adjectives attributed to OF $(\mathrm{r}=$ $0.33, \mathrm{p}<0.05)$. Among older children, the IAT score also correlated negatively with self-identification $(\mathrm{r}=-0.50, \mathrm{p}<0.01)$ and with body dissatisfaction $(r=-0.34, p<0.05)$. Several relations among the diverse explicit measures and the attitudes toward one's own body also appeared. Children who identified themselves with bigger body sizes showed lower levels of negative stereotypes toward OF. Also there were weak positive correlations between ideal identification and some of the explicit measures: children who chose thinner silhouettes like 'ideal bodies' showed higher preferences toward AF. 
Table 4. Correlations between implicit and explicit measures of anti-fat bias and personal body attitudes measures

\begin{tabular}{|c|c|c|c|c|c|c|c|c|c|c|c|}
\hline & 1 & 2 & 3 & 4 & 5 & 6 & 7 & 8 & 9 & 10 & 11 \\
\hline 1. Simple preferences AF & & & $0.41 * *$ & $0.46^{* * *}$ & & & & & & & \\
\hline 2. Simple rejections OF & & & $0.53 * * *$ & $0.51 * * *$ & & $0.27 * * *$ & & $0.20 *$ & & & \\
\hline 3. Sociometric preferences AF & & & & $0.55 * * *$ & & $0.25^{* *}$ & & & $-0.19 *$ & & \\
\hline 4. Sociometric rejections OF & & & & & $0.23 *$ & $0.41 * * *$ & & $0.29 * * *$ & & & \\
\hline 5. Positive attributes AF & & & & & & $0.68 * * *$ & & $0.34 * * *$ & & & \\
\hline 6. Negative attributes $\mathrm{OF}$ & & & & & & & $-0.21 *$ & $0.44 * * *$ & & & \\
\hline 7. Self-identification & & & & & & & & $-0.33 * * *$ & $0.33 * * *$ & $0.62 * * *$ & \\
\hline 8. Averted identification & & & & & & & & & $-0.23 * *$ & & \\
\hline 9. Ideal identification & & & & & & & & & & $-0.52 * * *$ & \\
\hline \multicolumn{12}{|l|}{ 10. Body dissatisfaction } \\
\hline 11. IAT score & & & & & & & & & & & \\
\hline
\end{tabular}

$\mathrm{AF}=$ Average-weight figures, $\mathrm{OF}=$ overweight figures.

$* \mathrm{p}<0.05 ; * * \mathrm{p}<0.01 ; * * * \mathrm{p}<0.001$.

Table 5. Predictors of sociometric preferences of $\mathrm{AF}$ and sociometric rejections of $\mathrm{OF}$

\begin{tabular}{lll}
\hline Predictors & $\beta$ & \\
\cline { 2 - 3 } & Sociometric preferences AF & Sociometric rejections OF \\
\hline Simple preferences - AF & $0.350 * * *$ & $0.370 * * *$ \\
Simple rejections - OF & $0.480^{* * *}$ & $0.400 * * *$ \\
Negative attributes - OF & & $0.260 * * *$ \\
Full predictor set & adjusted $\mathrm{R}^{2}=0.394 * *$ & adjusted $\mathrm{R}^{2}=0.479 * * *$ \\
\hline
\end{tabular}

$\mathrm{AF}=$ Average-weight figures, $\mathrm{OF}=$ overweight figures.

$* \mathrm{p}<0.05 ; * * \mathrm{p}<0.01 ; * * * \mathrm{p}<0.001$

\section{Regression Analyses}

In examining sociometric preferences of AF (table 5), the model was significant $\left(\mathrm{F}_{(2,114)}=38.10, \mathrm{p}=0.000\right.$, adjusted $\left.\mathrm{R}^{2}=0.394\right)$. Simple rejections of $\mathrm{OF}$ and simple preferences of AF were positive predictors of sociometric preferences of AF. On the other hand, three predictors (simple rejections of $\mathrm{OF}$, simple preferences of $\mathrm{AF}$ and negative traits attributed to $\mathrm{OF})$ significantly predicted the number of sociometric rejections received by $\mathrm{OF}\left(\mathrm{F}_{(3,111)}=35.91, \mathrm{p}=0.000\right.$, adjusted $\mathrm{R}^{2}=0.479$ ).

\section{Discussion}

Globally, our results confirm that participants hold considerable negative attitudes toward overweight peers, both at the explicit and the implicit level. However, we found differences in the intensity of this prejudice and its developmental course as a function of the tasks and the type of measurement used to assess anti-fat bias. Lastly, we also detected interesting relationships between participants' body image and some measures of prejudice.

In the explicit measures, we observed a strong favoritism for average-weight figures, which were most frequently chosen as the most liked. Participants indicated as well a greater willingness to engage in academic, recreational and social activities with them, and they were chosen as nice, smart or clean more often than the overweight children. Although we observed that the older participants displayed slightly more moderate levels of favoritism for this body type, high values found at all ages were sufficiently important to consider that people's weight is a very relevant trait for children's social choices through school ages.

On the other hand, overweight targets obtained negative scores in all the attitudinal measures: they were chosen by a majority as the least liked, they received a high amount of sociometric rejections, and they were chosen as mean, stupid or dirty more often than the average-weight targets. The use of two exemplars of each category considered in our work (AF and OF) allows us to conclude that the strong prejudice found in our results is not simply an artifact of the forced choice method.

Negative attitudes toward overweight peers (both simple and sociometric rejections) fell significantly with age, especially among the 10 - to 11 -year-olds. Furthermore, in this older age group, positive adjectives were almost equally distributed among both types of children while negative traits were attributed even more to average-weight figures than to the overweight ones.

All these results allow us to assume that explicit anti-fat prejudice tends to decrease as children approach pre-adoles- 
cence, in accordance with some previous studies in this area $[18,22,26,27,39]$ as well as in the area of ethnic prejudice [34] and prejudice against disabled children [59].

Our results with the implicit measure were very different. In general, IAT scores showed that by age 6, our participants appear to have formed detectable implicit attitudes toward different body types, and that this bias remains stable across ages, as observed regarding ethnic implicit attitudes [49, 50]. Also the associations found in our study (overweight-negative attributes; average-positive attributes) coincide with those reported in studies carried out with adults $[14,60]$ although the effect size that we observed was notably smaller than the sizes reported in these studies. Nevertheless, our mean score was similar (or even higher) to the effects observed in the studies on children's implicit ethnic attitudes commented below [49-50].

With regard to the questions related to personal body attitudes, the results also revealed some interesting age trends. First, although most of the participants identified with figures of an average body type, there was a slight tendency with age to choose figures that were slightly heavier. Secondly, in averted identification, while younger children massively rejected obese figures, older children rejected figures with severe underweight even more. Regarding the ideal body type, most of our participants pointed at the average figure or at the next thinnest figure. However, a non-negligible percentage of young children (most of them 6- to 7-year-old girls) chose one of the two severely underweight figures as the ideal body, an inclination that was absent in older participants. This result coincides with previous findings [61] and seems to indicate an early idealization of extreme thinness, mainly among girls. As suggested by some authors [36], this might have a long-term impact on the emergence of high levels of body dissatisfaction in adolescence and adulthood. Our results concerning body dissatisfaction showed in fact that the scores were slightly higher among girls than among boys.

We now comment on the type of relations observed between the diverse variables considered in our study. In general, there was practically no relationship between the responses in the explicit measures of prejudice and those obtained with the IAT, with some exceptions that are mentioned below. However, there were significant relationships among most of the explicit measures, and the linear regression analyses revealed an interesting result: simple preference and rejections ('I like', 'I do not like') were the measures that best predicted whom children would choose to share different activities. None of the other variables (neither explicit nor implicit stereotypes, or attitudes toward one's own body) predicted sociometric preferences, which seems to indicate that these biases are activated by very basic issues, possibly affective and aesthetic concerns. In the case of sociometric rejections of overweight children, the regression analysis also included negative attributions toward this target as a predictor variable. All these results are in accordance with the conclusions of other works [51] which state that one of the most important reasons for overweight prejudice is that fat people are perceived as being aesthetically unpleasant.

With reference to the relations between implicit and explicit measures of anti-fat attitudes, we only found such a correlation in the younger children (6-7 years) and only some relations between body image and the implicit bias in the group of older children (10-11 years). In the latter case, we observed that those who considered themselves to be thinner and who were satisfied with their bodies were, in turn, the ones with more implicit negative bias toward overweight. As we have mentioned, no measure of participants' BMI was taken in this study, so we cannot compare our results with previous studies that have used this objective information. It is interesting to remember that most of the researches with child samples find no relationship between children's real weight and their explicit attitudes toward overweight [16, 21, 25, 26]. We do not know what occurs with regard to implicit bias as there are no previous studies with children. An inverse relationship between one's own weight and the intensity of bias has been found in adults, with thinner people showing higher levels of anti-fat rejection [60]. In our study, this relationship appeared only in the case of implicit bias and, as mentioned, with selfperceived body type, but not with real body type.

As no previous studies have compared the developmental course of explicit and implicit anti-fat prejudices, we can only compare our results with the few works that were carried out in other domains such as ethnic attitudes [49]. In most of these studies, no correlations between explicit and implicit measures were found [41, 49]. These works also confirmed an asymmetric developmental pattern similar to the one in our study: a decrease in prejudice in explicit measures versus the stability of such prejudice in implicit measures. The hypothesis that these two types of attitudes dissociate during their developmental course obtains support from one of our results: the presence of a high correlation between explicit and implicit stereotypes in the group of younger children (6-7 years), but not in the rest.

Lastly, let us reflect on some of the implications of our results and those of previous studies. We can state that these findings confirm that aspects related to aesthetics and people's physical attractiveness (which, according to the Western norms, fit certain body prototypes) has acquired a very relevant role in children's personal relationships from a very early age. Children who grow up in Western societies idealize thinness from an early age and denigrate overweight, to which they associate a series of negative traits that have nothing to do with body type. As they grow older, they seem to reduce the open expression of their prejudices, in accordance with their increasing assimilation of positive social values and, maybe, their capacity to differentiate what may be the consequence of overweight (e.g. certain physical difficulties) from what is not (e.g. intelligence, goodness or hygiene). However, we must accept that some subtle and automatic associations may last for years as our IAT has shown. 
In addition to the results of this study, it is fact that the prejudices suffered by adults and children who stray from the Western aesthetic profile have expanded notably and can, in some cases, be stronger and have more serious psychological consequences than other kinds of prejudice such as those related to skin color $[19,62]$. In recent years, important efforts have been made to disseminate more positive and diverse representations of various stigmatized groups (such as ethnic minorities, disabled people etc.), but not of overweight people. It is essential to favor profound changes in the way that society presents information and promotes attitudes toward body size. Moreover, considering the severe consequences of obesity on people's health, interventions aimed at the reduction of overweight in these ages should avoid stigmatization of these people, promoting healthy life habits and encouraging body size acceptance.

As pointed out by Schwartz and Puhl [63], the message that 'it's bad to be fat' pervades the Western societies. Since overweight rates have greatly increased in last years, as well as negative perceptions about this people [64], there is an urgent necessity of expanding studies about weight bias. Understanding why, how and when these negative attitudes emerge and develop through school age should help us to design effective and adapted interventions aimed to protect the weakest members of our society: the children.

\section{Limitations and Future Directions}

There are several limitations of the present study that must be considered for improving future research. Firstly, the sociodemographic characteristics of our participants (all of them were white Spanish children from an upper-middle socioeconomic status with average body type) limit the generalization of our results. A second limitation was the use of photographs in the explicit tasks. As we have already pointed out, issues of comparable attractiveness must be considered. The use of new technologies to design materials opens a promising outlook in the elaboration of adequate stimuli in future studies.

Third, the mean score obtained in the IAT by our participants was quite low, especially in comparison to other biases measured in adults, such as racial prejudice, where $d$ is often $>1.0$. In this respect, in future studies we should improve our implicit measures, including other measures such as the personalized IAT [65] or the Affective Priming Task [66].

Research on the nature of explicit and implicit prejudices against overweight should continue to advance and develop more ambitious works that allow us to clarify the role of the different types of bias in current and even in future behavior. Moreover, the use of implicit measures in this field is still very rare; thus, multiple possibilities unfold for the study of attitudes in children, parents or educators. According to the proposal made by other authors [67] in their study of ethnic attitudes, it would be very interesting to analyze both types of bias in parents and children, and to appraise the influence of paternal attitudes at both levels. It would also be interesting to determine the extent to which parents' expectations about body image (their own and their children's) affect their children's development. In contrast to what occurs with other kinds of prejudice toward stable traits (i.e. racial), overweight is not an invariant characteristic and most people believe that it is controllable $[13,33]$. Therefore, children whose parents place extreme value on body image and aesthetic norms may dread becoming what their parents reject the most. Remember, previous studies have shown that children's overweight is frankly feared and rejected by a large quantity of adults, in some cases, even more feared than having an anorexic child or a learning disabled child [60]!

\section{Disclosure}

The authors declared no conflicts of interest

\section{References}

1 International Obesity Taskforce: IOTF demands action on childhood obesity crisis. Access February 20, 2008. www.iotf.org/media/IOTFmay12.htm.

2 Yach D, Stuckler D, Brownell KD: Epidemiologic and economic consequences of the global epidemics of obesity and diabetes. Nat Med 2006;12:62-66

3 Puhl RM, Brownell KD: Bias, discrimination, and obesity. Obes Res 2001;9:788-805.

$\checkmark 4$ Puhl RM, Brownell KD: Confronting and coping with weight stigma: An investigation of overweight and obese adults. Obesity 2006;14:1802-1815.

5 Hoek H, Van Hoeken D: Review of the prevalence and incidence of eating disorders. Int J Eat Disord 2003;34:383-396.

6 Thompson JK, Stice E: Thin-ideal internalization: Mounting evidence for a new risk factor for bodyimage disturbance and eating pathology. Curr Dir Psychol Sci 2001;10:181-183.
7 Fairburn CG, Doll HA, Welch SL, Hay PJ, Davies BA, O'Connor ME: Risk factors for binge eating disorder: a community-based, case-control study. Arch Gen Psychiatry 1998;55:425-432.

8 Neumark-Sztainer D, Falkner N, Story M, Perry C, Hannan PJ, Mulert S: Weight-teasing among adolescents: correlations with weight status and disordered eating behaviors. Int J Obes 2002;26:123131.

9 Wiseman CV, Gray JJ, Mosimann JE, Ahrens AH: Cultural expectations of thinness in women: an update. Int J Eat Disord 1991;11:85-89.

10 Weston M, Bliss D: Changing media images of weight; in Brownell KD, Puhl RM, Schwartz MB, Rudd L (eds): Weight Bias: Nature, Consequences and Remedies. New York, Guilford Press, 2005, pp 265-274.
11 Goodman N, Dornbusch SM, Richardson SA, Hastorf AH: Variant reactions of physical disabilities. Am Sociol Rev 1963;28:429-435.

12 Richardson SA, Goodman N, Hastorf AH, Dornbusch SM: Cultural uniformity in reaction to physical disabilities. Am Sociol Rev 1961;26:241-247.

13 Crandall CS: Prejudice against fat people: ideology and selfinterest. J Pers Soc Psychol 1994;66:882-894.

14 Teachman BA, Gapinski K, Brownell K, Rawlins M, Jeyaram S: Demonstrations of implicit anti-fat bias: the impact of providing causal information and evoking empathy. Health Psychol 2003;22:68-78.

15 Daniels SR: The consequences of childhood overweight and obesity. Future Child 2006;16;47-67.

16 Cramer P, Steinwert T: Thin is good, fat is bad: how early does it begin? J Appl Dev Psychol 1998;19: 429-451. 
17 Holub S: Individual differences in the anti-fat attitudes of preschool-children: the importance of perceived body size. Body Image 2008;5:317-321.

18 Penny H, Haddock G: Anti-fat prejudice among children: the 'mere proximity' effect in 5-10 year olds. J Exp Soc Psychol 2007;43:678-683.

19 Solbes I, Enesco I, Lago O, Rodríguez P: Actitudes hacia la diversidad humana (color de piel y complexión física). Un estudio con niños españoles y latinoamericanos residentes en Madrid; in Frías M, Corral V (eds): Niñez, Adolescencia y Problemas Sociales. Consejo Nacional de Ciencia y Tecnología (CONACyT) de México y Universidad de Sonora, 2009.

20 Brylinsky JA, Moore JC: The identification of body build stereotypes in young children. J Res Pers 1994;28:170-181.

-21 Kraig KA, Keel PK: Weight-based stigmatization in children. Int J Obes 2001;25:1661-1666.

22 Penny H, Haddock G: Children's stereotypes of overweight children. Br J Dev Psychol 2007;25:409_ 418.

23 Rich SS, Essery EV, Sanborn CF, DiMarco NM, Morales LK, LeClere SM: Predictors of body size stigmatization in Hispanic preschool children. Obesity 2008;16:11-17.

24 Wardle J, Volz C, Golding C: Social variation in attitudes to obesity in children. Int J Obes 1995;19: 562-569.

25 Davison KK, Birch LL: Predictors of fat stereotypes among 9- year-old girls and their parents. Obes Res 2004;12:86-94.

26 Davison KK, Schmalz DL, Young LM, Birch LL: Overweight girls who internalize fat stereotypes report low psychosocial well-being. Obesity 2008;16:30-38.

27 Latner JD, Stunkard AJ, Wilson TG: Stigmatized students: age, sex, and ethnicity effects in the stigmatization of obesity. Obes Res 2005;13:1226-1231.

28 Powlishta KK, Serbin, LA, Doyle A, White DR Gender, ethnic, and body type biases: the generality of prejudice in childhood. Dev Psychol 1994;30: 526-536.

29 Crystal DS, Watanabe H, Chin W: Intolerance of human differences: a cross-cultural and developmental study of American, Japanese, and Chinese children. J Appl Dev Psychol 1997;18:149-167.

-30 Tiggemann M, Anesbury T: Negative stereotyping of obesity in children: the role of controllability beliefs. J Appl Soc Psychol 2000;30;1977-1993.

-31 Wang SS, Brownell KD, Wadden TA: The influence of the stigma of obesity on overweight individuals. Int J Obes 2004:28:1333-1337.

32 McCabe MP, Ricciardelli LA, Sitaram G, Mikhail $\mathrm{K}$ : Accuracy of body size estimation: role of biopsychosocial variables. Body Image 2006;3;163-171.

- 33 Musher-Eizenman DR, Holub SC, Miller AB Goldstein SE, Edwards-Leeper L: Body size stigmatization in preschool children: the role of control attributions. J Pediatr Psychol 2004;29:613-620.

34 Aboud FE, Amato M: Developmental and socialization influences on intergroup bias; in Brown $\mathrm{R}$, Gaerther S (eds): Blackwell Handbook of Social Psychology: Intergroup Processes. Oxford, Blackwell, 2001, pp 65-85.
5 Bigler RS, Liben LS: A cognitive-developmental approach to racial stereotyping and constructive memory in Euro-American children. Child Dev 1993;64:1507-1518.

36 Dittmar H, Halliwell E, Ive S: Does Barbie make girls want to be thin? The effect of experimental exposure to images of dolls on the body image of 5- to 8-year-old girls. Dev Psychol 2006;42:283-292.

37 Latner JD, Schwartz MB: Weight bias in a child's world; in Brownell KD, Puhl RM, Schwartz RM, Rudd L (eds): Weight Bias: Nature, Consequences and Remedies. New York, Guilford Press, 2005, pp 54-67.

38 Tiggemann M, Wilson-Barrett E: Children's figure ratings: relationship to self-esteem and negative stereotyping. Int J Eat Disord 1998;23:83-88.

39 Rand CS, Wright BA: Continuity and change in the evaluation of ideal and acceptable body sizes across a wide age span. Int J Eat Disord 2000;28:90-100.

40 Enesco I, Guerrero S, Callejas C, Solbes I: Intergroup attitudes and social reasoning among majority and minority group children living in Spain; in Shery L, Killen M (eds): Intergroup Attitudes and Relations in Childhood through Adulthood. New York, Oxford University Press, 2008, pp 103-125.

41 Rutland A, Cameron L, Milne A, McGeorge P: Social norms and self-presentation: children's implicit and explicit intergroup attitudes. Child Dev 2005;76:451-466.

42 Greenwald AG, Banaji MR: Implicit social cognition: attitudes, self-esteem, and stereotypes. Psychol Rev 1995;102:4-27.

43 Dovidio JF, Kawakami K, Gaertner S: Implicit and explicit prejudice and interracial interaction. J Pers Soc Psychol 2002;82.62-68.

44 Cunningham WA, Johnson MK, Raye CL, Gatenby JC, Gore JC, Banaji MR: Separable neural components in the processing of black and white faces. Psychol Sci 2004;15:806-813.

45 Poehlman TA, Uhlmann E, Greenwald AG, Banaji MR: Understanding and using the Implicit Association Test: III. Meta-analysis of predictive validity. Unpublished manuscript. Available from MR Banaji, Department of Psychology, Harvard University, 33. Kirkland Street, Cambridge, MA 02138. 2004.

46 Bessenoff GR, Sherman JW: Automatic and controlled components of prejudice toward fat people: evaluation versus stereotype activation. Soc Cogn 2000;18:329-353.

47 Fazio RH: Multiple processes by which attitudes guide behaviour: the MODE model as an integrative framework. Adv Exp Soc Psychol 1990;23:75-109.

48 Dovidio JF: On the nature of contemporary prejudice: The third wave. J Soc Issues 2001;57:829-849.

49 Baron AS, Banaji MR: The development of implicit attitudes: evidence of race evaluations from ages 6,10 and adulthood. Psychol Sci 2006;17:53-58.

50 Dunham Y, Baron A, Banaji M: From American city to Japanese village: a cross-cultural investigation of implicit race attitudes. Child Dev 2006;77; 1268-1281.
1 Brochu PM, Morrison MA: Implicit and explicit prejudice toward overweight and average-weight men and women: testing their correspondence and relation to behavioral intentions. J Soc Psychol 2007;147:681-706

52 Tovée MJ, Cornelissen PL: Female and male perceptions of female physical attractiveness in frontview and profile. Br J Clin Psychol;2001;92:391-402.

53 Collins ME: Body figure perceptions and preferences among preadolescent children. Int J Eat Disord 1991;10:199-208

54 Greenwald AG, McGhee DE, Schwartz JL: Measuring individual differences in implicit cognition: the implicit association test. J Pers Soc Psychol 1998; 74:1464-1480.

55 Rudman LA, Greenwald AG, McGhee DE: Implicit self-concept and evaluative implicit gender stereotypes: self and ingroup share desirable traits. Pers Soc Psychol Bull 2001;27:1164-1178.

56 Dasgupta N, McGhee DE, Greenwald AG, Banaji MR: Automatic preference for white Americans: eliminating the familiarity explanation. J Exp Soc Psychol 2000;36:316-328.

57 Govan CL, Williams KD: Reversing or eliminating IAT effects by changing the affective valence of the stimulus items. J Exp Soc Psychol 2004;40:357-365.

58 Greenwald AG, Nosek BA, Banaji MR: Understanding and using the Implicit Association Test: I. An improved scoring algorithm. J Pers Soc Psychol 2003;85;197-216.

59 Sigelman CK, Miller TE, Whitworth LA: The early development of stigmatizing reactions to physical differences. J Appl Dev Psychol 1986;7:17-32.

60 Schwartz MB, Vartanian L, Nosek B, Brownell KD: The influence of one's own body weight on implicit and explicit anti-fat bias. Obes Res 2006;14:440-447.

61 Musher-Eizenman DR, Holub SC, Edwards-Leeper L, Persson AV,Goldstein SE: The narrow range of acceptable body types of preschoolers and their mothers. J Appl Dev Psychol 2003;24:259-272.

62 Neumark-Sztainer D, Story M, Faibisch L: Perceived stigmatization among overweight AfricanAmerican and Caucasian adolescent girls. J Adolesc Health 1998;23:264-270.

63 Schwartz MB, Puhl R: Childhood obesity: a societal problem to solve. Obes Rev 2003;4;57-71.

64 Latner JD, Stunkard AJ: Getting worse: the stigmatization of obese children. Obes Res 2003;11: 452-456.

65 Olson MA, Fazio RH: Reducing the influence of extra-personal associations on the Implicit Association Test: personalizing the IAT. J Pers Soc Psychol 2004;86:653-667.

66 Degner J, Wentura D: The Extrinsic Affective Simon Task as an instrument for indirect assessment of prejudice. Eur J Soc Psychol 2008;38:1033-1043.

67 Sinclair S, Dunn E, Lowery B: The relationship between parental racial attitudes and children's implicit prejudice. J Exp Soc Psychol 2005;41:283-289.

68 Cohen J: Statistical Power Analysis for the Behavioural Sciences. New York, Erlbaum, 1988. 